\title{
Signalling desistance? Crime attitudes, perceptions of punishment, and exposure to criminogenic models
}

\author{
Olivia K. Ha*, Evan C. McCuish, Martin A. Andresen, \& Raymond R. Corrado
}

Simon Fraser University, School of Criminology

* Address correspondence to Martin A. Andresen (andresen@sfu.ca). Simon Fraser University, School of Criminology 8888 University Drive Burnaby BC V5A 1S6

\begin{abstract}
Purpose: To examine individual perceptions of the consequences of crime, the role of criminogenic models, and whether rational choice and criminal social capital are informative of desistance during emerging adulthood.

Methods: Data from the Incarcerated Serious and Violent Young Offender Study were used to examine the relationship between different aspects of rational choice theories of desistance, criminogenic environment, and offending trajectories measured between ages 12-30, calculated using semi-parametric group-based modeling. Offending trajectories were then modeled using multinomial logistic regression.
\end{abstract}

Results: Trajectory analyses identified 3 desistance trajectories and 3 non-desistance trajectories. The strongest predictors of desistance trajectories included variables that relate to rational choices that considered the consequences of crime.

Conclusions: Rational choice and life course perspectives on desistance as complementary, with sources of informal social control operating in a manner that, along with other factors, helps structure an individual's consideration of, and importance placed on, the consequences of crime.

Key words: Criminogenic environment; desistance; rational choice; trajectories 
Acknowledgements: This work was supported by the Social Sciences and Humanities Research Council of Canada (410-2004-1875). 


\title{
Signalling desistance? Crime attitudes, perceptions of punishment, and exposure to criminogenic models
}

\begin{abstract}
Purpose: To examine individual perceptions of the consequences of crime, the role of criminogenic models, and whether rational choice and criminal social capital are informative of desistance during emerging adulthood.

Methods: Data from the Incarcerated Serious and Violent Young Offender Study were used to examine the relationship between different aspects of rational choice theories of desistance, criminogenic environment, and offending trajectories measured between ages 12-30, calculated using semi-parametric group-based modeling. Offending trajectories were then modeled using multinomial logistic regression.
\end{abstract}

Results: Trajectory analyses identified 3 desistance trajectories and 3 non-desistance trajectories. The strongest predictors of desistance trajectories included variables that relate to rational choices that considered the consequences of crime.

Conclusions: Rational choice and life course perspectives on desistance as complementary, with sources of informal social control operating in a manner that, along with other factors, helps structure an individual's consideration of, and importance placed on, the consequences of crime.

Key words: Criminogenic environment; desistance; rational choice; trajectories 


\section{Introduction}

As noted by Paternoster, Bachman, Bushway, and O’Connell (2015), early work investigating factors that facilitate desistance are principally concerned with the role of age-graded social processes. This line of research, particularly inspired by the work of Sampson and Laub (2003, 2005; also see Laub and Sampson 1993, 2001), views desistance as a process initiated via the acquisition of informal social controls such as marriage, parenthood, and employment. Less attention has been given to individual-level perceptions of the utility of crime and their importance for desistance (Paternoster et al. 2015). This is despite the specification of a succinct, rational choice-based perspective that considers subjective perceptions regarding the utility versus consequences of crime (e.g., Paternoster 1989). In their call to address the lack of attention to rational choice models in the examination of desistance, Paternoster et al. (2015) focused on how identity shapes an individual's criminal motives and perceptions of crime. Drawing from a signaling theory perspective (see Maruna 2012; Bushway and Apel 2012), direct measures of these motives and perceptions might be an important indicator of readiness to begin the desistance process. Thus, the purpose of the current study was to add to Paternoster et al.'s (2015) perspective by identifying whether specific preferences, concerns, and perceptions in adolescence regarding criminal behavior signal the individual's likelihood of desistance in adulthood.

Furthermore, in line with research showing that those deeply embedded in a criminogenic lifestyle are less likely to benefit from classic turning points such as marriage and employment (e.g., Blokland and Nieuwbeerta 2005), we examined whether an individual's criminogenic social environment implies that they are less responsive to traditional deterrence factors (e.g., Warr 1998). This approach was in line with several more recent approaches to integrating 
deterrence theories within existing perspectives (see Pratt et al., 2006 for a review). For example, Stafford and Warr (1993) described how perceptions of the likelihood of avoid punishment may vary according to the types of behavior modeled by persons within an individual's social environment. Although a greater degree of involvement in criminal behavior may reduce an individual's perception of the likelihood of detection (i.e., the experiential effect; Saltzman, Paternoster, Waldo, \& Chiricos, 1982), perceptions of detection may also be moderated by the degree to which one's peers are involved in delinquent and criminal behavior. Thus, the rationale that underlies the integration of these two theoretical perspectives is based on the notion that ones' social context could condition his/her perceptions of the costs and benefits of crime and, thus, inquiry into this line of reasoning could provide insight into why individuals respond differently to informal social controls and, accordingly, provide an explanatory factor for the desistance process.

For instance, identifying contexts in which offenders are unconcerned by the effect of criminal justice system intervention on their relationships would provide insight into factors that act as barriers to desistance. An individual who perceives themself as being successful or good at crime is likely to have a different response to the consequences of their actions than someone who does not see themself in that light. An individual that notes that the costs of crime are high may be perceived as signalling their readiness for desistance. However, if this individual also sees themselves as good at crime, they may believe that they can avoid detection and thus these negative consequences are unlikely to materialize. In effect, signalling perspectives must account for "false signals" by considering the context (e.g., high criminal social capital) in which statements about costs of crime are made. Furthermore, exposure to a social network consisting of others involved in crime may shape an offender's perception of the consequences of crime 
that, in turn, could impact the initiation of desistance. Assessments of individual perceptions with respect to criminal status are important to consider in this line of research because this perception may moderate how much one cares about the impact of their criminal behavior on others, a factor that could explain differential responses to formal and informal controls. In sum, having criminogenic models in ones' social network may help shape the perception that involvement in crime represents stake-in-conformity within the criminal network.

To test the propositions discussed above, the current study incorporates measures of criminogenic models to evaluate whether factors that are meant to serve as deterrents are mitigated by the presence of criminogenic models. Additionally, the assessment of adolescent social capital as interpersonal connections may prove fruitful as this form capital could influence an individual's perception of the risk and rewards of offending and, accordingly, factor into the initiation of desistance. Taken together, the current article aims to add to Paternoster et al.'s (2015) identity-based rational choice model of desistance by creating a conceptual model that captures (a) individual perceptions of crime that signal the initiation of desistance and (b) whether criminal social capital structures rational decision-making and what this means for the initiation of desistance. The main objective of this study is not to understand why the sixteenyear-old offender terminates their involvement in offending in adulthood. Instead, the focus is on whether holding certain perceptions of crime in adolescence "signals" the initiation of the desistance process in emerging adulthood. To explore these lines of analysis, retrospective and prospective data from Cohort 1 of the Incarcerated Serious and Violent Young Offender Study ( $n$ $=297$ ) are used to examine (a) individual perceptions of the consequences of crime, (b) the role of criminogenic models, and (c) whether these two theoretical frameworks (rational choice and 
criminal social capital) were informative of desistance during emerging adulthood (see Arnett, 2001).

\section{The role of decision making in crime involvement}

The rational choice approach posits that behavior is determined, in part, by weighing the costs and benefits associated with criminal offending (Clarke and Cornish 1985; Piliavin et al. 1986; Nagin 1998; McCarthy 2002). Treatments of rational choice often follow Becker's expected utility model of criminal decision making (see, for example, McCarthy 2002). The model proposed by Becker (1968) follows a relatively simple premise: individuals engage in crime when the expected utility from committing crime outweighs the expected consequences of crime (Matsueda, Kreager, and Huizinga 2006). Moreover, the decision to offend is influenced by individual preferences and attitudes toward risk (see Shover and Thompson 1992). Where an individual perceives the risks associated with crime to be low but the rewards and availability of criminal opportunities high, he/she will make a rational calculation to offend.

Rational choice research commonly focuses on the responsiveness of crime to individuallevel risk perceptions (Loughran et al. 2016). This literature elaborates on subjective perceptions of individuals, as opposed to objective measures, such as arrest or clearance rates. Much of this literature is concerned with the primary relationship between subjective risk perceptions and

offending. Recent works have demonstrated that subjective risk perceptions are dynamic and rationally responsive to new information, derived from samples of the general population (Lochner, 2007), high-risk youth (Matsueda, Kreager, and Huizinga 2006), serious offenders (Anwar and Loughran, 2011), and the peer environment (Garnefiski and Okma 1996; Rolison and Scherman 2003). 


\section{Rational choice and desistance}

Early considerations of rational choice and desistance primarily emphasized the deterrent effect of incarceration (e.g., Ehrlich 1973) and offender perceptions of police and the likelihood of detection (e.g., Sampson and Cohen 1988). To help understand some of the lack of initial support for the impact of specific deterrence on avoiding involvement in offending Later expansions of deterrence theory emphasized capturing an individual's prior experiences with criminal behavior (Saltzman et al., 1982) as well as experiences of that individual's peer group (Stafford \& Warr, 1993). Bringing these two perspectives together, Piquero and Paternoster (1998) found that experiential effects and vicarious experiences were both related to an individual's description of their likelihood of drinking and driving. However, less attention has been given to how personal and vicarious experiences relate to perceptions of the likelihood of getting caught, and how the interaction between these factors relates to actual involvement in criminal behavior.

Another way in which deterrence theory was expanded upon was through Paternoster's integration of deterrence and criminal motivation into a broader rational choice model of common delinquent offending. The aim of Paternoster's (1989) study was to examine the impact of rational decision making on different offending decisions, including decisions to desist from crime. Paternoster (1989) found that non-legal considerations, primarily the participation of peers and peer approval of such behavior had significant impact on one's decision to offend. Similarly, the decision to desist from crime was found to be unrelated to considerations of legal threats. Overall, Paternoster (1989) concluded that empirical tests of a rational choice model ought to account for sanction threats and that theoretical constructs from the rational choice perspective need be applied to more serious offenders for which legal sanctions carry more consequences. Shover and Thompson (1992) addressed some of these recommendations in their 
examination of costs and benefits of crime participation for formerly serious offenders. They showed that perceptions of the likelihood of detection and low expectations about the rewards of crime involvement improved the likelihood of termination from offending. However, as noted by Paternoster (2010), focusing solely on legal-based consequences provide an incomplete picture of an individual's perceptions of the costs associated with crime involvement.

More recently, Paternoster and colleagues (2015) revisited the discussion on desistance, once again arguing for a rationally based perspective. They put forth that theories focusing on either social processes or cognitive and emotional transformations portray individuals who commit criminal offenses as unintentional actors, at the mercy of social forces upon which they have little control. Because minimal attention has been expended toward the role of individual subjective processes such as those that underlie the rational choice perspective, Paternoster and colleagues (2015) believe that existing explanations of why individuals quit crime are rather incomplete. Their perspective is premised on a model of rational choice wherein the preferences and behaviors of an individual are shaped by his/her reasoning, this model relies on individualistic mental processes to explain why people desist from crime (Paternoster et al. 2015). Accordingly, Paternoster and colleagues (2015) highlight the importance of including the role of individual cognitive processes in the decision to desist from crime, something that is lacking in the existing scholarship. How individuals think about criminal behavior and their perceptions of the impact of criminal justice system intervention on their relationships would seem particularly important for signaling readiness for change in criminal behavior. Densley and Pyrooz's (2017) conceptual model described how gang members may use specific statements to detail their status as an ex-gang member. Similarly, statements about recognizing the costs of crime may signal that an individual is signaling their desire to be an ex-offender. However, the 
meaningfulness of such statements should be interpreted with consideration for an individual's criminogenic social environment. For desistance, the costs of crime may outweigh the benefits only in contexts where one's network lacks criminogenic models that may encourage or reward criminal behavior. With Stafford and Warr's (1993) description of vicarious experiences in mind, exposure to criminogenic models may inhibit the positive impact of factors such as perceptions of the likelihood of getting caught that are believed to promote desistance. In other words, by including measures of criminogenic models, the current study aimed to evaluate whether factors that are meant to deter individuals from crime involvement are mitigated by the presence of criminogenic models, thus assessing whether criminal social capital structures rational decisionmaking.

\section{Method}

\subsection{Sample and procedures}

Cohort 1 of the Incarcerated Serious and Violent Young Offender Study (see Corrado \& McCuish, 2018) formed the basis for the current research. As part of this study, between 1998 and 2001, youth (ages 12-19) were interviewed in open and secure custody facilities within the Greater Vancouver Regional District and surrounding areas. The current study concerned a subsample of adjudicated youth $(n=297)$ who were interviewed concerning their responses to questions about what would deter them from offending, whether they think about the consequences of criminal behavior, their motivation for criminal behavior, and whether persons within their social network were also involved in crime. Although the sample was predominantly White, Indigenous youth are overrepresented in this study. Specifically, only $6.2 \%$ of the 
population of British Columbia self-identified as Indigenous (Statistics Canada, 2013), whereas $21.2 \%(n=63)$ of this study's participants self-identified as such.

Interviews with adjudicated youth were conducted with informed consent from the British Columbia Ministry of Child and Family Development (MCFD). MCFD acts as the legal guardian to all youth in custody and their consent allowed the research team to approach youth in custody centers throughout British Columbia. While in the custody center, youth were approached by a member of the research team and asked to participate. Participants were eligible for the study if they met several criteria: (1) were English-speaking, (2) demonstrated an understanding of interview questions (e.g., had no noticeably severe deficits in IQ), and (3) were willing to provide accurate information. Participating youth were interviewed by research assistants in an isolated interview room to help ensure confidentiality. All participants were read and given a copy of an information sheet that explained the purpose of the study, how information would be collected (e.g. interview and file information), and that all information would be kept confidential unless the participant made a direct threat against themselves or someone else.

\subsection{Measures}

4.2.1. Demographic characteristics and predictors of desistance. Demographic factors included gender (male/female) and ethnicity (White, Indigenous, and non-Indigenous Minority) and were self-reported by participants at the time of their interview. Subjective perceptions regarding criminal motives and attitudes, deterrence factors, and the likelihood of detection were measured to capture signals that may be informative of a rational decision to begin the process of desistance. Regarding motivations and attitudes toward crime, youth were asked whether they 
committed crime for money $(0=$ not at all to sometimes; $1=$ mostly to totally $)$. Attitudes supportive of crime were captured by a scale comprised of three items (1-7 scale) that asked youth whether they thought their offense was fun, whether they were glad that they did it, and whether they would do it again (Cronbach's alpha $=0.68) .{ }^{1}$ Regarding deterrence from crime, in line with Fagan and Piquero (2007) subjective perceptions of both the likelihood of detection and the consequences of punishment were measured for both crime in general and with regard to specific offences. Youth were asked to provide the probability that they would stop committing crime if they were not bored/seeking thrills and whether the current sentence will influence their future decision to commit an offense. To measure whether youth consider the likelihood of detection, participants were asked to rate the probability that they would get caught if they tried to commit the same offense again. Consequences of crime were measured using four separate items: whether the youth thinks about general consequences of their crime, whether they think about their parents' response to their criminal behavior, and the degree to which their involvement in crime impacted their relationship with police (formal consequences) and parents (informal consequences). Finally, to address the study's aim of understanding whether the meaningfulness of subjective perceptions as signals for desistance varied according to an individual's social environment, youth were asked to report on a scale from 1-5 the proportion of their friends who were delinquent $($ one $=$ none; five $=$ all). Youth also reported the number of different family members who were involved in crime (e.g., mother, father, brother, sister, aunt, uncle, etc.). The questionnaire is provided in an appendix at the end of the paper.

\footnotetext{
${ }^{1}$ These attitudinal measures may be considered opinions, but we will use this terminology to be consistent with the literature. Moreover, it is important to note the alpha level for this measure is moderate.
} 
The descriptive statistics for these variables are reported in Table 1 . There was very little variation in the age at first interview, with an average of 16.5 and a standard deviation of 1.23 years. The data consist dominantly of males who are White. On average, youth reported that their involvement in crime was more impactful on their relationship with police than on their relationship with parents. This is perhaps because criminal behavior in the family of origin was common for members of the sample. Similarly, most youth reported that at least some of their peers were delinquent. Money was a major motivational factor for youth involvement in crime (approximately a third of the sample). In terms of factors that may deter future offending, the average probability that a participant would stop committing crime if they were not bored or seeking thrills was nearly 0.50 . Youth believed that they had about a 50/50 chance of getting caught if they repeated their current offense in the future. On average, the probability that youth considered their parents' response to their crime was low, which again may relate to this group's tendency to come from a criminogenic family background. Because of the nature of this sample (incarcerated youth offenders), these descriptive statistics are not surprising.

$<$ Insert Table 1 About Here $>$

4.2.2. Offending outcomes. Offending was measured using official data from British Columbia Corrections' computerized system, Corrections Network (CORNET), that contains information on the criminal offense, date of conviction, and sentence received. Every criminal charge that resulted in a conviction was coded from age 12, the age of criminal responsibility in Canada, until, on average, age $31.47(S D=1.26$; range $=30-35)$. To ensure comparisons of offending were made with all participants having equal opportunity to offend, only convictions incurred between ages 12-30 were examined (i.e., the age of the youngest person in the sample); 
moreover, these data only include offenses committed while not in custody, such that offenders are structurally precluded from committing offenses during that time. Between the ages of 12 and $303.4 \%(n=10)$ of the sample died and 4.4\% $(n=13)$ moved outside the province. For these cases, convictions after the age of death or move were coded as missing rather than as 'zero'. To illustrate the severity of the sample, participants averaged 23.24 convictions $(S D=$ 18.57) between ages 12-30. Over the same period, participants spent approximately three years in custody. The amount of time incarcerated is particularly noteworthy for highlighting the importance of exposure time, which was accounted for in the semi-parametric group-based model (SPGM) described below.

\subsection{Analytic strategy}

SPGM (see Nagin and Land 1993) is considered an appropriate analytical method for identifying longitudinal patterns of specific outcomes, such as offending, and is used in various fields of research such as developmental psychology and criminology (e.g., Nagin and Tremblay 1999). Examining offending trajectories rather than recidivism was important considering the former better captures more concerning patterns of offending compared to the latter (Bushway, Paternoster, and Brame 2003). Offending trajectories were estimated from ages 12-30 and we use a zero-inflated Poisson model to account for excess zero values. These values occur partially because of incarceration (the nature of our data does not include any in-custody offenses, as stated above) as well as non-offending in any given year, particularly for the low-rate offenders. The use of a zero-inflated model mitigates this issue because it is a linear combination of a logit model and a count model. If the logit component carries little weight in the analyses, little (or no) weight is assigned to this component in the estimation. The SPGM analysis included a measure 
of exposure time, equal to the proportion of each year of age that was spent in the community rather than custody, to control for time at risk. Number of days incarcerated was divided by 367 because exposure must be a non-zero value and some offenders spent 366 days incarcerated during leap years.:

$$
\text { Exposure }_{j i}=1-(\text { Number of Days Incarcerated/367), }
$$

where $j$ is the respondent and $i$ is the year of observation.

The output of the trajectory analysis is a set of offending groups: adolescence-limited offenders, other desisting offenders, persistent offenders, and so on. It is important to keep in mind that these trajectories are derived from the analysis and are not necessarily naturally occurring groups (Skardhamar 2010). Because of the qualitative nature of these offending groups, ordinary least squares (OLS) regression models are not appropriate because the dependent variable is a set of mutually exclusive categories that do not lay on a continuum. Multinomial logistic regression, developed by McFadden (1981), is a class of statistical methods referred to as categorical data analysis. These methods specify the dependent variable qualitatively (categories or groups), such as offending groups from a trajectory analysis or local crime clusters in an analysis of local spatial autocorrelation (Andresen 2011). The result of estimation is the probability of the dependent variable being a particular category occurring considering a set of independent variables.

The multinomial logistic model is expressed as follows:

$$
\operatorname{Prob}(Y=J)=\frac{e^{X \beta_{i}}}{1+\sum_{i=1}^{J} e^{X \beta_{i}}},
$$

where $Y$ is the offending category, $J+1$ is the number of alternatives, $e$ is the natural exponential function, $X$ is the matrix of independent variables, and $\beta_{i}$ are estimated parameters. All variables 
are included in the specification of equation 2. Additionally, we conduct a number of moderation analyses through the use of interaction effects (number of family members with a criminal record and proportion of friend the delinquent considers delinquent with a number of other variables), with only one interaction variable added to the original formulation (variables listed in Table3) at a time. The interaction effects are important because they consider the joint effect of two (or more) variables. Rather than considering only the independent effect of the number of family members with a criminal record, we consider the effect of this variable in conjunction with a number of risk factors; for example, the effect of increasing the proportion of delinquent friends and whether or not their friends think they are strong and tough. We report statistically significant relationships at the 5\% level. We include all variables in our analyses in order to avoid removing relevant variables because of multicollinearity, that could lead to omitted variable bias.

Unlike OLS that minimizes the squared errors through the choice of $\beta$, multinomial logistic regression maximizes a likelihood function by choosing $\beta$ (Greene 2000; Kennedy 2003; Wooldridge 2002). As such, there is no $R^{2}$ measure calculated in multinomial logistic estimation. Rather, there is a variant of $R^{2}$, a Pseudo- $R^{2}$, for multinomial logistic regression provided by McFadden (1974), the likelihood ratio index:

$$
L R I=1-\frac{\ln L}{\ln L_{0}},
$$

where $\ln L$ is the $\log$-likelihood function representing the final model and $\ln L_{0}$ is the $\log$ likelihood function only containing the constant term. This Pseudo- $R^{2}$ index, similar to $R^{2}$, is bounded by 0 and 1 , with values greater than 0.20 considered to be an excellent fit (McFadden 1974); we include this McFadden Pseudo- $R^{2}$ in the tables of output, provided below. Lastly, we report the relative risk ratios (RRR) for ease of interpretation in our results, below. 


\section{Results}

Trajectory analyses were conducted in SAS 9.4 using the Proc TRAJ add-on developed by Jones et al. (2001). Model identification involves identifying the number and shape of the offending trajectories. The zero-inflated Poisson (ZIP) model with quadratic functional form was used to estimate the distribution of the offending trajectories. Based on Bayesian Information Criteria (BIC) values, a six-group quadratic model resulted in a BIC value closest to zero. Jeffrey's scale of the evidence of the Bayes factor was used to validate the retention of the six-group solution. Using the formula $e^{B I C i-B I C j}$, where values of $B_{i j}$ greater than ten indicate strong evidence for model ' $i$ ' (see Nagin, 2005), there was strong evidence in both analyses for a six-group model over other models $\left(B_{i j}>10\right)$. Fit statistics for the six-group model (see Table 2$)$ indicated that classification accuracy, based on the average posterior probability of accurately assigning individuals to a particular trajectory, was high for all six trajectories (range $=0.85-0.92$ ). Odds of correct classification (OCC) was used to help provide confidence that individuals were assigned to the appropriate trajectory, and was calculated as:

$$
\mathrm{OCC}_{\mathrm{g}}=\left(\text { AvePPg }_{\mathrm{g}} /\left(1-\mathrm{AvePP}_{\mathrm{g}}\right)\right) /\left(\prod_{\mathrm{g}} /\left(1-\prod_{\mathrm{g}}\right)\right)
$$

where $\prod_{\mathrm{g}}$ is the estimated size of group g (see Skardhamar, 2010). OCC values were all greater than five, indicating high classification accuracy (Skardhamar, 2010).

\section{$<$ Insert Table 2 About Here $>$}

Based on their shape, the trajectories shown in Figure 1 were labeled: low rate $9.8 \%$ of the sample), adolescence-limited (33.0\%), high rate desisters (10.8\%), stable low (24.2\%), high rate persistent (13.8\%), and escalators (8.4\%). Though we may initially appear to have a low percentage of adolescence-limited and large percentages of higher rate offenders, this is because 
our sample is of incarcerated individuals, not from the general population. We considered desistance to be a process of reduced levels of offending that reach a level of offending indistinguishable from zero (e.g., Bushway et al. 2003). Offending outcomes across different stages of the life course were examined and compared for each of the six trajectories (see Table 2). Key to identifying trajectories consistent with this definition of desistance was the pattern of offending that followed the end of emerging adulthood, which was defined as between ages 1825 (see Arnett 2001). Three trajectories showed a consistent decline in level of offending that reached a near-zero point by ages 26-30: low rate, adolescence-limited, and high rate desisters. Although the stable low and high rate persistent groups also showed a pattern of lower levels of offending across the three developmental stages examined, between ages 26-30 these groups were still averaging a relatively high rate of offending that was significantly greater than that of the low rate, adolescence-limited, and high rate desister groups. Because of our interest in desistance, we collapsed the stable low, high rate persistent, and escalator trajectories into one category ( $46.5 \%$ of the sample) to act as the reference category (non-desisters) to which the three desistance-based categories were compared in the multinomial logistic regression analysis.

\section{<Insert Figure 1 About Here $>$}

The results from the multinomial logistic regression predicting the desister categories are shown in Table 3. Overall, with a McFadden Pseudo- $R^{2}$ of 0.180 , we consider this to be a very good fit. It is worth noting here that there is some consistency across the desister categories regarding statistically significant variables in the model, but there is most definitely enough to indicate the need for separate desister categories, as identified in the trajectory model. In other words, the different desistance trajectories appear to be characterized by different pathways to desistance. Beginning with the low rate group, increases in attitudes supportive of crime 
decreased the odds of membership in this group relative to the non-desister reference category. Youth that reported their peers viewed them as strong and tough were significantly less likely to be in this group compared to non-desisters. Youth that suggested that they would stop committing crime if not bored were significantly less likely to be in the low rate group compared

to the non-desisters. This implies that those that were not committing crime out of boredom/thrill seeking were more likely to be associated with the low rate trajectory. In terms of the consequences of crime, increases in the probability of considering parents' response to their criminal behavior significantly increased the odds of membership in the low rate trajectory compared to non-desisters. Similarly, an increase in the extent to which youth perceived their relationship with police to be impacted by their current sentence was associated with an increased likelihood of membership in the low rate trajectory. Finally, an increase in the proportion of one's peer group that were delinquent was associated with a decreased odds of being in in the low rate trajectory.

\section{<Insert Table 3 About Here>}

For the adolescence-limited group, being female significantly increased the odds of membership in this group compared to the non-desister reference category. Like the low rate group, an increase in the extent to which youth perceived their relationship with police to be impacted by their current sentence was associated with an increased likelihood of membership in the adolescence-limited trajectory compared to the non-desister group. Lastly, looking at the high rate desisters, participants that reported being motivated to commit crime for money and youth that reported that their peers viewed them as strong and tough were significantly less likely to be in this group compared to non-desisters. With respect to criminogenic models, an increase in the number of different family members involved in crime significantly increased the odds of 
membership in the high rate desister group compared to the non-desister group. That having a greater number of criminogenic models was associated with a desistance trajectory compared to trajectories that showed a level of persistence over the first decade of adulthood is likely because the high rate desisters had the highest peak level of offending in adolescence. Although speculative, for youth with family members involved in crime, entering adulthood may have afforded them with more of an opportunity to exert independence from family and exposed themselves to environments that were more conducive to desistance.

As stated above, to address whether the impact of different factors influencing desistance/persistence varied according to a participant's criminogenic environment, a series of moderation analyses were also conducted. The top half of Table 4 shows the moderating effect of family criminogenic models on all non-demographic factors and the bottom half of Table 4 shows the moderating effect of peer criminogenic models on all non-demographic factors. Each interaction effect (e.g., Sentence Impacts Relationship with Police * Number of Family Members with a Criminal Record) was examined while controlling for the main effects of both variables and all other variables that were included in Table 3. Variables were not mean-centered as they had a meaningful zero point (see Dalal and Zickar 2012). The variables used to create the interaction effects were specified so that that higher values of the interaction term signified lower levels of criminogenic models but higher levels of deterrence.

Regarding family criminality, increases in the probability of getting caught for the same offense significantly increased the odds of being in the low rate trajectory compared to the nondesister reference category against the backdrop of lower levels of family criminality. The same observation was made when examining the interaction between family criminality and whether the youth considered their parents' response prior to committing an offense. When 
looking at the adolescent limited trajectory, an increased perception that offending impacted relationships with police significantly increased the odds of being in the adolescent limited trajectory compared to the nondesister trajectory as level of family criminality also decreased. For peer delinquency, an increase in the likelihood of considering parental response to crime significantly increased the odds of being in the high rate desister trajectory compared to the reference category when observed in the context of lower levels of peer delinquency. Finally, increases in participants' perceptions of how their offense impacted their relationship with police significantly increased the odds of membership in the low rate trajectory compared to the nondesister trajectory when in the context of lower having a lower proportion of delinquent peers. In sum, having lower levels of family/peer criminality appeared to be especially important for interpreting the effect of rational choice constructs (e.g., probability of getting caught again) on desistance.

\section{$<$ Insert Table 4 About Here $>$}

\section{Discussion}

The desistance literature has tended to focus on turning points and the role of informal social controls (e.g., Sampson and Laub 2003) and in the process the decision to cease delinquent activities and the social environment in which this decision is made has been somewhat neglected. We view these rational choice and life course perspectives on desistance as complementary, with sources of informal social control operating in a manner that, along with other factors, helps structure an individual's consideration of, and importance placed on, the consequences of crime (also see Paternoster 2010). Whereas Paternoster et al. (2015) focused on how an individual's identity may shape decisions for involvement in crime, we focused on (a) 
specific perceptions of the costs of crime that may influence this decision and (b) whether criminogenic environments attenuate these perceptions. For example, if youth come from crimeprone families or believe that they are good at crime, they may be less likely to consider the impact of their criminal behavior on their relationship with their parents or less likely to believe in their likelihood of getting caught. Similarly, although justice system involvement may typically negatively impact bonds to family and other life domains (e.g., Lopes et al. 2012), this negative impact may be less likely for youth from crime-prone families (e.g., "my parents will be proud of me") and the importance of selection effects is well-documented (e.g., Blokland and Nieuwbeerta 2005). Thus, the current study examined the impact of deterrence factors on desistance, including whether youth consider the consequences of crime, what these consequences are perceived to be, and whether a youth's criminogenic environment mitigates the relevance of rational choice measures used to predict desistance.

The current study relied on a sample of incarcerated male and female offenders from the ISVYOS $(n=297)$ to measure offending trajectories between ages 12-30. This sample is considered to include particularly serious and violent youth, and as evidence of this, the sample averaged over 23 convictions and over three years in custody during the study period. The severity of the sample is relevant because the motives for crime and the sources of social support may be qualitatively distinct from community-based studies of youth. Trajectory analyses produced six distinct trajectories. In most trajectory studies (e.g., Piquero 2008 for a review), interest is in identifying risk factors for a persistent offending trajectory. The current study used a different approach as interest was in how deterrence and other factors promoted desistance. Specifically, three offending trajectories were characterized by continued offending during adulthood (ages 18 to 30 ) and three trajectories were characterized by desistance (i.e., a process 
of slowing down in level of offending in adulthood that reached a level indistinguishable from zero). The three non-desister trajectories (stable low, high rate persistent, and escalator trajectories) were collapsed into a reference category to which the three different desistance trajectories were compared. The three desistance trajectories were not aggregated because of differences in the timing of desistance and rate of prior offending. Variations in significant factors across the different desistance patterns re-emphasized the importance of disaggregation. Overall, the study findings illustrated that youth perceptions of criminal behavior involvement may help signal a readiness for desistance (e.g., Maruna 2012)

Beginning with the low rate trajectory, an increase in pro-crime attitudes, reports of peer perceptions of strength and toughness, reports of crimes committed out of boredom, and increases in the proportion of delinquent peers decreased the likelihood of an individual's assignment to this trajectory compared to the non-desister reference group. Furthermore, considering parental responses to criminal behavior and experiencing a strained relationship with police as a result of criminal involvement increased the odds of membership in the low rate group compared to the reference group. Therefore, measures capturing attitudes toward crime, deterrence from crime and, consequences of crime were most relevant in distinguishing the low rate group of desisters from the reference group of non-desisters. It appeared that the low rate group was low in criminal social capital; they did not have many delinquent friends, their friends did not view these individuals as having qualities (i.e., toughness) conducive to criminal behavior, and they did not have particularly pro-crime attitudes. These youth cared about the impact of their crime on relationships with adult authority figures and how such figures would respond. Similarly, as the likelihood of considering the probability of getting caught increased, so too did the odds of association with a trajectory characterized by desistance if such youth had 
a less criminogenic peer network. However, the main effect of the measure of the likelihood of getting caught was not significant. This may be related to the failure to account for experiential effects, whereby individuals that are more actively involved in criminal behavior view the risk of detection as being lower (e.g., Pogarsky and Piquero 2003; Shover and Thompson 1992).

Although experiential effects were not directly tested in the current study, the observation that peer network moderated the effect of perceptions of detection is initial evidence that exposure to delinquent peers may be a type of vicarious (e.g., Paternoster \& Piquero, 1995) experiential effect that can serve as a proxy for personal experiences. These findings also bring together life course theory assertions of the importance of informal social controls (e.g., Sampson and Laub 1997) with rational choice decisions to offend or not offend (e.g., Clarke and Cornish 1985; Cusson and Pinsonneault 1986). It is not simply that the existence of a relationships that insulates an individual from crime; rather, these relationships lead adolescents involved in a low rate of crime to rethink their involvement in crime because of its impact on how parents and police might react. However, the impact of some of the abovementioned factors was attenuated if such youth came from a highly criminogenic family background (see Table 4).

For the adolescence-limited group, like the low rate group, the extent to which youth perceived their relationship with police to be impacted by their current sentence increased the odds of being in this trajectory compared to the non-desister reference group. However, a moderation analysis showed that the relationship between rapport with police and desistance was moderated by a more criminogenic family background. This indicated that if youth came from a highly criminogenic family background, parents and other relatives may hold negative attitudes towards police that impact a youth's perception about the meaningfulness of having their relationship with police harmed by their involvement in crime. Community policing programs 
are less effective when risk factors are ignored (Sherman and Eck 2002) and although "hot spots" and other macro-level indicators are often used to identify risk, findings from the current study indicate that community policing strategies attempting to build relationships with young offenders should consider the young offender's familial environment that may act as a barrier to building rapport.

Finally, participants who reported money as the motivating factor for their crime and those who reported being perceived by peers as strong and tough were significantly less likely to belong to the high rate desister group. On the other hand, an increase in the number of family members involved in crime increases the odds of membership in the high rate desister category over the non-desister reference group. Although speculative, it is noteworthy that the high rate desister group had the highest peak level of offending of any offending trajectory, yet also showed the steepest decline in level of offending during adulthood (see Figure 1). It is possible that the transition to adulthood allowed youth in the high rate desister trajectory to become more independent from their family and thus "knife off" (Sampson and Laub 2005, p. 17) their connections to these criminogenic models. Similarly, entry into adulthood includes new constraints on time that limit opportunities to associate with delinquent peers (e.g., Warr 1998). Being away from criminogenic models could present opportunities for exposure to environments that are more conducive to desistance. The limited number of factors influencing desistance for high rate desisters may be because these factors were measured while individuals from this group were still deeply embedded in a pattern of criminal behavior. This points to the importance of repeated measures of deterrence constructs in adulthood.

\section{Limitations and future research}


It is important to note that given the age at first interview with the offenders and the timing of desistance (very similar, on average, see Figure 1), it is possible that their attitudes/perceptions are a reflection of the fact that they had already begun desisting; such a situation would be consistent with Laub and Sampson's (2003) notion of "desistance by default." However, despite the closeness of age at first interview and the timing of desistance, there are very few in our sample whose interview occurred over the age of 17 and even fewer who are classified as desisters. As such, though we cannot definitively state that our hypothesized causal order is at play, because of the low count of potential counter examples in our data we are confident in our interpretations. However, it is important to note that future study designs should consider this issue when investigating attitudes/perceptions and subsequent desistance.

On a related note, a key aspect of desistance research is the examination of withinindividual change or stability, but the research design of the ISVYOS does not currently allow for this assessment. Moreover, the process of desistance must be maintained in adulthood, yet the current study did not have measures of deterrence during this period. Such information was likely necessary for more fully understanding the pattern of desistance shown by the high rate desister trajectory. That said, this approach captured the perspective of the criminal justice system practitioner working with incarcerated youth. The practitioner's identification of the incarcerated youth's negative perceptions towards crime may help signal a change in identity (e.g., Densley and Pyrooz 2017) and suggest that the youth would benefit from services that help support their desire to change. Future research should bring together this signaling-based perspective with Paternoster et al.'s (2015) identity-based perspective to more fully describe rational choice perspectives on desistance (e.g., whether an identity change initiates perceptions about the costs of crime). 
Also related to measurement, the current study did not provide a complete test of rational choice perspectives on desistance. Future research should ask participants to weigh the consequences of custody against the benefits of offending and examine the impact of formal consequences of justice system involvement (e.g., length of incarceration) that may 'shock' (Cusson and Pinsonneault 1986) an offender into reassessing the costs and benefits of crime. The current study examined the moderating effect of a criminogenic social environment on deterrence factors. Other factors that may impact perceptions of consequences of crime involvement, such as marriage and employment, should also be examined as more positive social roles that increase perceptions about the negative consequences of crime. The current study also used official data, which are often associated with underestimation of offending. However, incarcerated adolescent offenders are disproportionately responsible for more serious offenses, which tend to be underreported in self-report studies (e.g., Stouthamer-Loeber, Loeber, Stallings, and Lacourse 2008).

The smaller sample implies that it may be underpowered for the examination of interaction effects (e.g., Aguinis 1995). There are two implications of this. First, actual moderation effects may have gone unobserved. Second, the significant moderation effects that were observed were likely overestimated (i.e., Type $M$ error; Gelman and Carlin 2014), which makes it necessary to avoid interpreting the interaction effects odds ratios as accurate reflections of the magnitude of this relationship. This may also explain the mixed results, reported above. Nevertheless, small samples are necessary to help grow this body of research.

The rational decision to cease criminal and delinquent activities may be bound by human agency, criminal identity and motivation, criminogenic models in an individual's social environment, and access to sources of informal social control that are valued by the individual. 
Most desistance research has examined these theoretical perspectives in isolation or as theories to compare and contrast rather than integrate. The current study stepped towards understanding the bounded nature of decisions to cease criminal and delinquent activity by examining whether an individual's criminal connections moderated the influence of different deterrence factors. Although consideration of crime involvement's impact on relationships with parents and police was associated with desistance, the importance of such considerations for desistance varied by level of criminogenic peer and/or family environment. Similarly, as the likelihood of considering the probability of getting caught increased, so too did the odds of association with a trajectory characterized by desistance; however, this was true only for those with a more criminogenic peer network. In other words, believing that the probability of detection is high may be less likely to deter individuals when the criminal justice sanctions resulting from detection will not negatively impact their social ties. Future research is needed to better understand the temporal relationship between identity, social environment, and perceptions of the costs of crime (e.g., LeBel, Burnett, Maruna, and Bushway 2008). 


\section{References}

Aguinis, H. (1995). Statistical power with moderated multiple regression in management research. Journal of Management, 21(6), 1141-1158.

Andresen, M.A. (2011). Estimating the probability of local crime clusters: The impact of immediate spatial neighbors. Journal of Criminal Justice, 39(5), 394 - 404.

Arnett, J. J. (2001). Conceptions of the transition to adulthood: Perspectives from adolescence through midlife. Journal of Adult Development, 8(2), 133-143.

Anwar, S., \& Loughran, T. A. (2011). Testing a Bayesian learning theory of deterrence among serious juvenile offenders. Criminology, 49(3), 667-698.

Becker, G. S. (1968). Crime and punishment: An economic approach. Journal of Political Economy, 76(2), $169-217$.

Blokland, A. A., \& Nieuwbeerta, P. (2005). The effects of life circumstances on longitudinal trajectories of offending. Criminology, 43(4), 1203-1240.

Bushway, S. D., \& Apel, R. (2012). A signaling perspective on employment-based reentry programming. Criminology \& Public Policy, 11(1), 21-50.

Bushway, S. D., Paternoster, R., \& Brame, R. (2003). Examining the prevalence of criminal desistance. Criminology, 41(2), 423-448.

Clarke, R. V., \& Cornish, D. B. (1985). Modeling offenders' decisions: A framework for research and policy. Crime and Justice, 6, 147-185.

Coleman, J. S. (1990). Rational organization. Rationality and Society, 2(1), 94-105.

Cornish, D. B., \& Clarke, R. V. (1986). Situational prevention, displacement of crime and rational choice theory. In K. Heal \& G. Laycock (Eds.), Situational crime prevention: From theory into practice (pp. 1 - 16). London, UK: HMSO. 
Corrado, R.R., \& McCuish, E.C. (2018). Key findings and operational lessons in the measurement of psychopathy within the Incarcerated Serious and Violent Young Offender Study. In M. DeLisi (Ed.), The Routledge international handbook of psychopathy and crime. New York, NY: Routledge.

Cusson, M., \& Pinsonneault, P. (1986). The decision to give up crime. In D. B. Cornish \& R. V. Clarke (Eds.), The reasoning criminal: Rational choice perspectives on offending (pp. 7282). New York, NY: Springer-Verlag.

Dalal, D. K., \& Zickar, M. J. (2012). Some common myths about centering predictor variables in moderated multiple regression and polynomial regression. Organizational Research Methods, 15(3), $339-362$.

Densley, J. A., \& Pyrooz, D. C. (2017). A signaling perspective on disengagement from gangs. Justice Quarterly, https://doi.org/10.1080/07418825.2017.1357743.

Ehrlich, I. (1973). Participation in illegitimate activities: A theoretical and empirical investigation. Journal of Political Economy, 81(3), 521 - 565.

Fagan, J., \& Piquero, A. R. (2007). Rational choice and developmental influences on recidivism among adolescent felony offenders. Journal of Empirical Legal Studies, 4(4), 715-748.

Garnefiski, N., \& Okma, S. (1996). Addiction-risk and aggressive/criminal behaviour in adolescence: Influence of family, school and peers. Journal of Adolescence, 19(6), 503512.

Gelman, A., \& Carlin, J. (2014). Beyond power calculations: assessing type S (sign) and type M (magnitude) errors. Perspectives on Psychological Science, 9(6), 641-651.

Greene, W.H. (2000). Econometric analysis (4th ed.). Upper Saddle River, NJ: Prentice Hall. 
Jones, B. L., \& Nagin, D. S. (2007). Advances in group-based trajectory modeling and an SAS procedure for estimating them. Sociological Methods \& Research, 35(4), 542-571.

Jones, B. L., Nagin, D. S., \& Roeder, K. (2001). A SAS procedure based on mixture models for estimating developmental trajectories. Sociological Methods \& Research, 29(3), 374-393.

Kennedy, P. (2003). A guide to econometrics (5th ed.). Malden, MA: Blackwell Publishing.

Laub, J., \& Sampson, R.J. (2003). Shared beginnings, divergent lives: Delinquent boys to age 70. Cambridge, MA: Harvard University Press.

Laub, J. H., \& Sampson, R. J. (2001). Understanding desistance from crime. Crime and Justice, 28, 1-69.

Laub, J. H., \& Sampson, R. J. (1993). Turning points in the life course: Why change matters to the study of crime. Criminology, 31(3), 301-325.

Laub, J. H., Nagin, D. S., \& Sampson, R. J. (1998). Trajectories of change in criminal offending: Good marriages and the desistance process. American Sociological Review, 63(2), 225238.

LeBel, T. P., Burnett, R., Maruna, S., \& Bushway, S. (2008). The 'chicken and egg' of subjective and social factors in desistance from crime. European Journal of Criminology, 5(2), 131-159.

Lochner, L. (2007). Individual perceptions of the criminal justice system. American Economic Review, 97(1), 444-460.

Lopes, G., Krohn, M.D., Lizotte, A.J., Schmidt, N.M., Vasquez, B.E., \& Bernburg, J.G. (2012). Labeling and cumulative disadvantage: The impact of formal police intervention on life chances and crime during emerging adulthood. Crime \& Delinquency, 58(3), 456-488 
Loughran, T. A., Paternoster, R., Chalfin, A., \& Wilson, T. (2016). Can rational choice be considered a general theory of crime? Evidence from individual-level panel data. Criminology, 54(1), 86-112.

McCarthy, B. (2002). New economics of sociological criminology. Annual Review of Sociology, 28, 417-442.

McFadden, D. (1974). Conditional logit analysis of qualitative choice behavior. In P. Zarembka (Ed.), Frontiers in econometrics (pp. 105 - 142). New York, NY: Academic Press.

McFadden, D. (1981). Econometric models of probabilistic choice. In C.F. Manski \& D. McFadden (Eds.), Structural analysis of discrete data using econometric applications (pp. 198 - 272). Cambridge, MA: MIT Press.

Maruna, S. (2012). Elements of successful desistance signaling. Criminology \& Public Policy, 11(1), 73-86.

Matsueda, R. L., Kreager, D. A., \& Huizinga, D. (2006). Deterring delinquents: A rational choice model of theft and violence. American Sociological Review, 71(1), 95-122.

Nagin, D. S. (1998). Criminal deterrence research at the outset of the twenty-first century. Crime and Justice, 23, 1-42.

Nagin, D. (2005). Group-based modeling of development. Cambridge, MA: Harvard University Press.

Nagin, D. S., \& Land, K. C. (1993). Age, criminal careers and population heterogeneity: Specification and estimation of a nonparametric, mixed Poisson model. Criminology, $31(3), 327-362$. 
Nagin, D. S., \& Tremblay, R. E. (1999). Trajectories of boys' physical aggression, opposition, and hyperactivity on the path to physically violent and nonviolent juvenile delinquency. Child Development, 70(5), 1181-1196.

Paternoster, R. (1989). Decisions to participate in and desist from four types of common delinquency: Deterrence and the rational choice perspective. Law and Society Review, 23(1), 7-40.

Paternoster, R. (2010). How much do we really know about criminal deterrence? The Journal of Criminal Law and Criminology, 100(3), 765-824.

Paternoster, R., \& Bushway, S. (2009). Desistance and the" feared self": Toward an identity theory of criminal desistance. The Journal of Criminal Law and Criminology, 99(4), 1103 - 1156.

Paternoster, R., Bachman, R., Bushway, S., Kerrison, E., \& O’Connell, D. (2015). Human agency and explanations of criminal desistance: Arguments for a rational choice theory. Journal of Developmental and Life-Course Criminology, 1(3), 209-235.

Piliavin, I., Gartner, R., Thornton, C., \& Matsueda, R. L. (1986). Crime, deterrence, and rational choice. American Sociological Review, 51(1), 101-119.

Piquero, A. R., Blumstein, A., Brame, R., Haapanen, R., Mulvey, E. P., \& Nagin, D. S. (2001). Assessing the impact of exposure time and incapacitation on longitudinal trajectories of criminal offending. Journal of Adolescent Research, 16(1), 54-74.

Piquero, A. R., \& Pogarsky, G. (2002). Beyond Stafford and Warr's reconceptualization of deterrence: Personal and vicarious experiences, impulsivity, and offending behavior. Journal of Research in Crime and Delinquency, 39, 153-186. 
Pogarsky, G., \& Piquero, A. R. (2003). Can punishment encourage offending? Investigating the “resetting" effect. Journal of Research in Crime and Delinquency, 40(1), 95-120.

Pratt, T. C., Cullen, F. T., Blevins, K. R., Daigle, L. E., \& Madensen, T. D. (2006). The empirical status of deterrence theory: A meta-analysis. In F.T. Cullen, J.P. Wright, \& K.R. Blevins (Eds.), Taking stock: The status of criminological theory (V. 15), 367-396. New Brunswick, NJ: Transaction Publishers.

Rolison, M. R., \& Scherman, A. (2003). College student risk-taking from three perspectives. Adolescence, 38(152), $689-704$.

Saltzman, L., Paternoster, R., Waldo, G. P., \& Chiricos, T. G. (1982). Deterrent and experiential effects: The problem of causal order in perceptual deterrence research. Journal of Research in Crime and Delinquency, 19, 172-189.

Sampson, R. J., \& Cohen, J. (1988). Deterrent effects of the police on crime: A replication and theoretical extension. Law and Society Review, 22(1), 163-189.

Sampson, R. J., \& Laub, J. H. (2003). Life-course desisters? Trajectories of crime among delinquent boys followed to age 70. Criminology, 41(3), 555-592.

Sampson, R. J., \& Laub, J. H. (2005). A life-course view of the development of crime. The Annals of the American Academy of Political and Social Science, 602(1), 12-45.

Stafford, M. C., \& Warr, M. (1993). A reconceptualization of general and specific deterrence. Journal of Research in Crime and Delinquency, 30, 123-135.

Sherman, L.W. \& Eck, J.E. (2002). Policing for prevention. In L.W. Sherman, D. Farrington, \& B. Welsh (Eds.), Evidence based crime prevention (pp. 295 - 329). New York, NY: Routledge. 
Shover, N., \& Thompson, C. Y. (1992). Age, differential expectations, and crime desistance. Criminology, 30(1), 89-104.

Skardhamar, T. (2010). Distinguishing facts and artifacts in group-based modeling. Criminology, 48(1), 295-320.

Statistics Canada (2013). Aboriginal peoples in Canada: First Nations people, Métis and Inuit. Ottawa, ON: Statistics Canada.

Stouthamer-Loeber, M., Loeber, R., Stallings, R., \& Lacourse, E. (2008). Desistance from and persistence in offending. In R. Loeber, D. P. Farrington, M. Stouthamer-Loeber, \& H. R. White (Eds.), Violence and serious theft: Development and prediction from childhood to adulthood (pp. 269-308). New York, NY: Routledge.

Warr, M. (1998). Life-course transitions and desistance from crime. Criminology, 36(2), 183 216.

Wooldridge, J.M. (2002). Econometric analysis of cross section and panel data. Cambridge, MA: MIT Press. 


\section{Tables and Figures}

Table 1. Descriptive statistics, explanatory variables $(n=297)$

\begin{tabular}{|c|c|c|c|}
\hline & $M(S D) / n(\%)$ & Min. & Max. \\
\hline \multicolumn{4}{|l|}{ Demographic Characteristics } \\
\hline Age at first interview & $16.5(1.23)$ & 13 & 19 \\
\hline Male & $251(84.5 \%)$ & - & - \\
\hline Female & $46(15.5 \%)$ & - & - \\
\hline \multicolumn{4}{|l|}{ Ethnicity } \\
\hline White & $180(60.6 \%)$ & - & - \\
\hline Indigenous & $63(21.2 \%)$ & - & - \\
\hline Non-Indigenous Minority & $54(18.2 \%)$ & - & - \\
\hline \multicolumn{4}{|l|}{ Crime Motives and Attitudes } \\
\hline Crime Motivated by Money & $197(67.5 \%)$ & - & - \\
\hline Pro-Crime Attitude & $9.71(4.97)$ & 3 & 21 \\
\hline Friends think I'm Strong and Tough & $162(55.5 \%)$ & - & - \\
\hline \multicolumn{4}{|l|}{ Deterrence from Crime } \\
\hline Would not Commit Crime if not Bored & $0.44(0.37)$ & 0.00 & 1.00 \\
\hline The Current Sentence Will Influence Decision to Commit an Offense & $0.52(0.40)$ & 0.00 & 1.00 \\
\hline \multicolumn{4}{|l|}{ Likelihood of Detection } \\
\hline Probability of Getting Caught if Committing Same Offense & $0.57(0.34)$ & 0.00 & 1.00 \\
\hline \multicolumn{4}{|l|}{ Consequences of Crime } \\
\hline Thinks about Consequences before Committing an Offense & $0.42(0.38)$ & 0.00 & 1.00 \\
\hline Before I Commit a Crime... I think about what My Parents Might Do & $0.25(0.33)$ & 0.00 & 1.00 \\
\hline Sentence Impacts Relationship with Police & $58.44(40.36)$ & 0 & 100 \\
\hline Sentence Impacts Relationship with Parents & $27.89(32.46)$ & 0 & 100 \\
\hline \multicolumn{4}{|l|}{ Criminogenic Models } \\
\hline Number of Family Members with a Criminal Record & $1.13(1.15)$ & 0 & 7 \\
\hline Proportion of Friends that Youth Considers Delinquent & $3.33(1.10)$ & 1 & 5 \\
\hline
\end{tabular}


Table 2. Fit statistics for a zero inflated Poisson model with quadratic functional form $(n=297)$

\begin{tabular}{|c|c|c|c|c|c|c|}
\hline & \multicolumn{6}{|c|}{ Offending Trajectories: Full Adulthood (12-30) } \\
\hline & $\begin{array}{c}\text { Low Rate } \\
(n=29)\end{array}$ & $\begin{array}{c}\mathrm{AL} \\
(n=98)\end{array}$ & $\begin{array}{c}\text { HRD } \\
(n=32)\end{array}$ & $\begin{array}{c}\text { Stable Low } \\
(n=72)\end{array}$ & $\begin{array}{c}\text { HRP } \\
(n=41)\end{array}$ & $\begin{array}{l}\text { Escalators } \\
(n=25)\end{array}$ \\
\hline \multicolumn{7}{|l|}{ Model Fit } \\
\hline Mdn. posterior probability & 0.88 & 0.96 & 1.00 & 1.00 & 0.98 & 0.98 \\
\hline Avg. posterior probability & $0.85(0.16)$ & $0.88(0.16)$ & $0.91(0.14)$ & $0.95(0.11)$ & $0.92(0.11)$ & $0.90(0.17)$ \\
\hline Range & $0.51-1.00$ & $0.50-1.00$ & $0.54-1.00$ & $0.52-1.00$ & $0.62-1.00$ & $0.43-1.00$ \\
\hline $\mathrm{OCC}$ & 5.47 & 7.26 & 9.80 & 18.74 & 11.22 & 8.64 \\
\hline \multicolumn{7}{|l|}{ Offending Outcomes } \\
\hline Convictions (12-17) & $2.66(1.82)^{\mathrm{b}, \mathrm{c}, \mathrm{d}, \mathrm{e}, \mathrm{f}}$ & $8.38(8.38)^{\mathrm{a}, \mathrm{c}, \mathrm{d}, \mathrm{e}, \mathrm{f}}$ & $17.94(9.67)^{\mathrm{a}, \mathrm{b}, \mathrm{d}}$ & $11.68(7.47)^{\mathrm{a}, \mathrm{b}, \mathrm{c}, \mathrm{e}}$ & $22.51(8.16)^{\mathrm{a}, \mathrm{b}, \mathrm{d}, \mathrm{f}}$ & $13.76(6.41)^{\mathrm{a}, \mathrm{b}, \mathrm{e}}$ \\
\hline Convictions (18-25) & $1.66(4.84)^{\mathrm{b}, \mathrm{c}, \mathrm{d}, \mathrm{e}, \mathrm{f}}$ & $1.71(1.77)^{\mathrm{c}, \mathrm{d}, \mathrm{e}, \mathrm{f}}$ & $10.82(10.56)^{\mathrm{a}, \mathrm{b}, \mathrm{d}}$ & $8.97(6.96)^{\mathrm{a}, \mathrm{b}, \mathrm{e}, \mathrm{f}}$ & $18.63(7.53)^{\mathrm{a}, \mathrm{b}, \mathrm{c}, \mathrm{d}}$ & $21.73(14.07)^{\mathrm{a}, \mathrm{b}, \mathrm{d}}$ \\
\hline Convictions (26-30) & $0.31(1.67)^{\mathrm{d}, \mathrm{e}, \mathrm{f}}$ & $0.13(0.34)^{\mathrm{d}, \mathrm{e}, \mathrm{f}}$ & $0.52(0.85)^{\mathrm{d}, \mathrm{e}, \mathrm{f}}$ & $3.18(2.74)^{\mathrm{a}, \mathrm{b}, \mathrm{c}, \mathrm{e}, \mathrm{f}}$ & $7.23(4.83)^{\mathrm{a}, \mathrm{b}, \mathrm{c}, \mathrm{d}}$ & $12.64(7.91)^{\mathrm{a}, \mathrm{b}, \mathrm{c}, \mathrm{d}}$ \\
\hline
\end{tabular}

Notes. AL = Adolescence Limited; HRD = High Rate Desisters; HRP = High Rate Persisters; OCC = Odds of Correct Classification; means are reported with standard deviations in parentheses.

${ }^{a}$ Significantly different from Low Rate, ${ }^{b}$ significantly different from AL, ${ }^{c}$ significantly different from HRD, ${ }^{d}$ significantly different from Stable Low, ${ }^{\mathrm{e}}$ significantly

different from HRP, ${ }^{\mathrm{f}}$ significantly different from Escalators. 
Table 3. Predicting offending trajectories: Multinomial logistic regression results

\begin{tabular}{|c|c|c|c|}
\hline & Low Rate & Adolescence-Limited & High Rate Desisters \\
\hline & $\operatorname{RRR}(95 \% \mathrm{CI})$ & $\operatorname{RRR}(95 \% \mathrm{CI})$ & $\operatorname{RRR}(95 \% \mathrm{CI})$ \\
\hline \multicolumn{4}{|l|}{ Demographic Characteristics } \\
\hline Female & $1.07(0.25-4.65)$ & $2.63(1.16-5.94)^{*}$ & $0.13(0.01-1.23)$ \\
\hline \multicolumn{4}{|l|}{ Ethnic Group $^{\dagger}$} \\
\hline Indigenous & $0.33(0.06-1.79)$ & $1.01(0.48-2.14)$ & $0.94(0.31-2.82)$ \\
\hline Non-Indigenous Minority & $1.61(0.47-5.55)$ & $1.82(0.77-4.32)$ & $1.36(0.36-5.13)$ \\
\hline \multicolumn{4}{|l|}{ Crime Motives and Attitudes } \\
\hline Crime Motivated by Money & $0.59(0.19-1.78)$ & $0.64(0.33-1.26)$ & $0.28(0.11-0.74)^{*}$ \\
\hline Pro-Crime Attitude & $0.79(0.69-0.92)^{* *}$ & $0.95(0.89-1.02)$ & $1.05(0.95-1.16)$ \\
\hline Friends think I'm Strong and Tough & $0.24(0.09-0.67)^{* *}$ & $0.59(0.32-1.09)$ & $0.36(0.15-0.88)^{*}$ \\
\hline \multicolumn{4}{|l|}{ Deterrence from Crime } \\
\hline Would not Commit Crime if was not Bored & $0.12(0.03-0.54)^{* *}$ & $0.80(0.35-1.82)$ & $0.82(0.24-2.83)$ \\
\hline The Current Sentence Will Influence Decision to Commit an Offense & $1.18(0.30-4.67)$ & $1.39(0.60-3.24)$ & $0.36(0.10-1.26)$ \\
\hline \multicolumn{4}{|l|}{ Likelihood of Detection } \\
\hline Probability of Getting Caught if Committing Same Offense & $0.54(0.12-2.39)$ & $0.68(0.26-1.77)$ & $3.07(0.74-12.76)$ \\
\hline \multicolumn{4}{|l|}{ Consequences of Crime } \\
\hline Thinks about Consequences before Committing an Offense & $0.35(0.08-1.58)$ & $1.45(0.60-3.52)$ & $1.55(0.42-5.73)$ \\
\hline Before I Commit a Crime... I think about what My Parents Might Do & $6.49(1.32-31.99)^{*}$ & $2.51(0.92-6.87)$ & $0.92(0.18-4.63)$ \\
\hline Sentence Impacts Relationship with Police & $1.02(1.00-1.03)^{*}$ & $1.01(1.01-1.02)^{* *}$ & $1.00(0.99-1.01)$ \\
\hline Sentence Impacts Relationship with Parents & $1.00(0.99-1.02)$ & $1.00(0.99-1.01)$ & $1.00(0.99-1.02)$ \\
\hline \multicolumn{4}{|l|}{ Criminogenic Models } \\
\hline Number of Family Members with a Criminal Record & $0.67(0.40-0.98)$ & $0.84(0.62-1.13)$ & $1.60(1.14-2.25)^{*}$ \\
\hline Proportion of Friends that Youth Considers Delinquent & $0.62(0.40-0.98)^{*}$ & $0.93(0.69-1.24)$ & $0.78(0.51-1.19)$ \\
\hline Model Fit & \multicolumn{3}{|c|}{$\mathrm{LL}=-269.94 ;$ McFadden Pseudo- $R^{2}=0.180 ; \chi^{2}(45)=118.75, p<.001$} \\
\hline
\end{tabular}

Notes. The three non-desister trajectories were used as the reference category to which all other trajectories were compared; RRR $=$ Relative Risk Ratio; * $p<.05, * * p<.01$; 'WWhite' is reference category. 
Table 4. Interaction effects between criminogenic models and constructs from rational choice theories of desistance

Trajectory Group

Membership as the

Outcome of Interest

$\underline{\text { Interaction Term }}$

Crime Motivated by Money *Number of Family Members with a Criminal Record Pro-Crime Attitude *Number of Family Members with a Criminal Record Friends think I'm Strong and Tough *Number of Family Members with a Criminal Record Would not Commit Crime if was not Bored *Number of Family Members with a Criminal Record The Current Sentence Will Influence Decision to Commit an Offense *Number of Family Members with a Criminal Record Probability of Getting Caught if Committing Same Offense * Number of Family Members with a Criminal Record Thinks about Consequences before Committing an Offense *Number of Family Members with a Criminal Record Before I Commit a Crime... I think about what My Parents Might Do *Number of Family Members with a Criminal Record Sentence Impacts Relationship with Police *Number of Family Members with a Criminal Record Sentence Impacts Relationship with Parents *Number of Family Members with a Criminal Record Crime Motivated by Money *Proportion of Friends that Youth Considers Delinquent Pro-Crime Attitude *Proportion of Friends that Youth Considers Delinquent

Friends think I'm Strong and Tough *Proportion of Friends that Youth Considers Delinquent Would not Commit Crime if was not Bored *Proportion of Friends that Youth Considers Delinquent The Current Sentence Will Influence Decision to Commit an Offense *Proportion of Friends that Youth Considers Delinquent Probability of Getting Caught if Committing Same Offense *Proportion of Friends that Youth Considers Delinquent Thinks about Consequences before Committing an Offense *Proportion of Friends that Youth Considers Delinquent Before I Commit a Crime... I think about what My Parents Might Do *Proportion of Friends that Youth Considers Delinquent Sentence Impacts Relationship with Police *Proportion of Friends that Youth Considers Delinquent Sentence Impacts Relationship with Parents * Proportion of Friends that Youth Considers Delinquent
n.s.
n.s.
n.s.
n.s.
n.s.

Low Rate $>$ ND

n.s.

Low Rate $>$ ND

$\mathrm{AL}>\mathrm{ND}$ n.s.

n.s.

n.s.

n.s.

n.s.

n.s.

Low Rate $>$ ND

n.s.

$\mathrm{HRD}>\mathrm{ND}$

n.s.

n.S.

Notes. Non-desister trajectory group is reference category. AL = Adolescence Limited; HRD = High Rate Desisters; ND = Non-Desister; N.S. $=$ nonsignificant interaction effects $(p \geq$

$.05)$. Greater than/less than signs indicate whether odds of trajectory group membership were higher or lower relative to the reference category. The variables used to create the

interaction effects were specified so that that higher values of the interaction term represented lower levels of criminogenic models and higher levels of deterrence. 
Figure 1. Trajectory classifications, 6-group solution

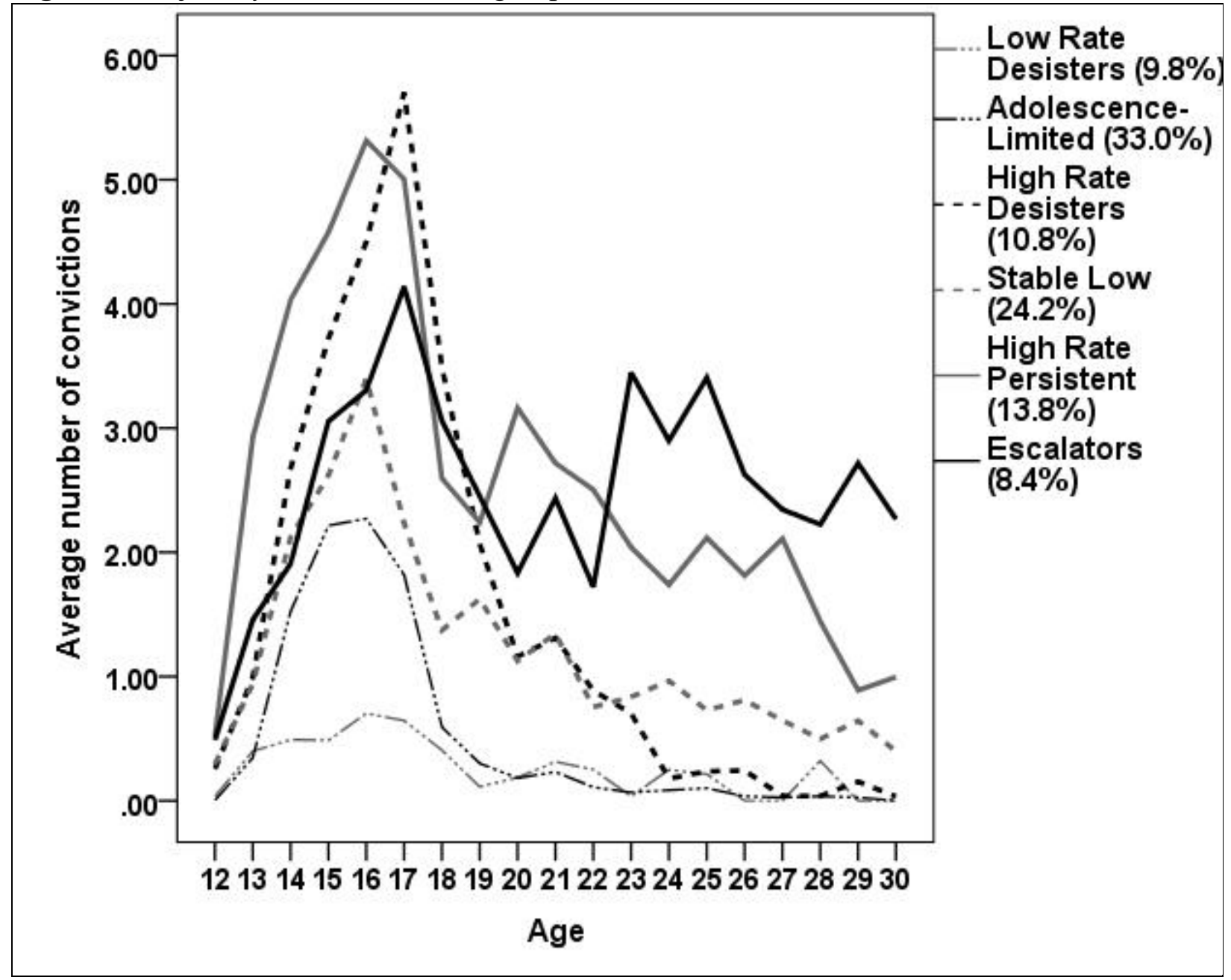




\section{Appendix}

\section{Crime Motives and Attitudes}

How many of your friends think you're strong and tough?

(1) All, (2) Most, (3) Some, (4) Hardly Any, (5) None

Describe your feeling about the current offense you committed using the seven-point scale:

Sorry(1)/Glad(7); Would not do it again(1)/Would do it again(7); Not fun(1)/Fun(7)

When you do crime, it is because you want to get things/money:

(1) Totally, (2) Mostly, (3) Somewhat, (4) Hardly at all, (5) Not at all

\section{Deterrence from Crime}

The following would play a role in my decision to commit an offence, if I was to commit one, in the first 12 months following my release:

(a) If I was bored/thrills

This (present) sentence will stop me from committing another crime.

\section{Likelihood of Detection}

Indicate what you believe the changes are that you would get caught by the police if you committed any of the following crimes:

(a) Commit the same offence again

\section{Consequences of Crime}

Before I commit a crime, I think about:

(a) What my parents will think/do

(b) What will happen to me if I'm caught

My sentence makes it difficult for me to get along with:

(a) My parents

(b) Police Officers

\section{Criminogenic Models}

In your opinion, how many of your friends are delinquents or criminals:

(2) All, (2) Most, (3) Some, (4) Hardly Any, (5) None

Thinking about all your family members, who in your family... has a criminal record? 